\title{
A unique case of unicuspid aortic valve with severe regurgitation combined with coronary-pulmonary fistula
}

\author{
Matej Novak' ${ }^{1}$ Vladimir Cerny' ${ }^{1}$ Zuzana Hlubocka², Jaroslav Hlubocky³ ${ }^{3}$ Petr Kuchynka², Lukas Lambert ${ }^{1}$

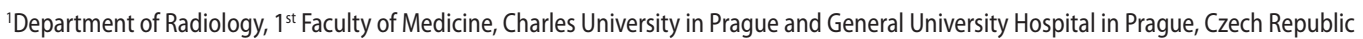 \\ ${ }^{2} 2^{\text {nd }}$ Department of Medicine - Department of Cardiovascular Medicine, $1^{\text {st }}$ Faculty of Medicine, Charles University in Prague and General University Hospital \\ in Prague, Prague, Czech Republic \\ ${ }^{3} 2^{\text {nd }}$ Department of Surgery - Department of Cardiovascular Surgery, $7^{\text {st }}$ Faculty of Medicine, Charles University in Prague and General University Hospital in Prague, \\ Prague, Czech Republic
}

\author{
Correspondence to: \\ Petr Kuchynka, MD, PhD, \\ $2^{\text {nd }}$ Department of Medicine - \\ Department of Cardiovascular \\ Medicine, \\ General University Hospital \\ in Prague, \\ $1^{\text {st }}$ Faculty of Medicine, Charles \\ University in Prague, \\ U Nemocnice 2, 128 08, Prague 2, \\ Czech Republic, \\ phone: + 420224962634 \\ e-mail: petr.kuchynka@lf1.cuni.cz \\ Copyright by the Author(s), 2022 \\ DOI: 10.33963/KP.a2021.0178 \\ Received: \\ October 30, 2021 \\ Accepted: \\ December 11, 2021 \\ Early publication date: \\ December 12, 2021
}

Congenital heart diseases may be considered in isolation, as well as in connection with other anomalies. Prevalence of the unicuspid aortic valve is only $0.02 \%$ in the adult population, which makes this congenital malformation very rare [1]. Moreover, it has male predominance [2]. It usually presents in the third to fifth decade of life with severe aortic stenosis, less frequently with aortic regurgitation. Diagnosis can be made with echocardiography, computed tomography (CT), or cardiac magnetic resonance. The preferred treatment of patients with severe aortic valve stenosis or regurgitation is surgical repair or replacement of the affected valve.

The coronary artery fistulas (CAFs) are rare abnormalities, and their prevalence is estimated to be $0.9 \%$ in the adult population. CAFs are usually asymptomatic due to their small size, although they may cause pulmonary hypertension or high cardiac output heart failure. CAFs may be diagnosed with selective coronary angiography, although electrocardiogram-gated CT has higher sensitivity in the detection of small fistulas [3]. Symptomatic CAFs can be treated with surgical ligation or percutaneous transcatheter closure. To our best knowledge, the combination unicuspid aortic valve with CAF has not been described so far.

We present a case of a 36-year-old woman with progressive exertional dyspnoea the New York Heart Association (NYHA) class III, with severe aortic regurgitation (vena contracta $7 \mathrm{~mm}$, prominent holodiastolic reversal in descending aorta), and only mild stenosis (mean pressure gradient $25 \mathrm{~mm} \mathrm{Hg}$, aortic valve area
$1.62 \mathrm{~cm}^{2}$ ) due to the unicuspid aortic valve combined with coronary-pulmonary fistula. The patient first underwent transthoracic echocardiography detecting the presence of the dilated left ventricle (left ventricular end-diastolic diameter $65 \mathrm{~mm}$; left ventricular ejection fraction $62 \%$ ) due to severe aortic regurgitation (leaflet prolapse; calcifications and fibrotic changes of the valve) and the suspicion of unicommissural unicuspid valve was raised (Supplementary material, Video S1). These findings were subsequently confirmed with 2D and 3D transesophageal echocardiography (Figure 1A, B and Supplementary material, Video S2). Electrocardiogram-gated CT coronary angiography was performed showing the calcified unicuspid aortic valve (Agatston calcium score of the aortic valve of 1249) (Figure 1D). Moreover, the CT depicted a coronary anomaly, a coronary artery originating in the ascending aorta close to the ostium of the right coronary artery and terminating in the pulmonary artery (Figure 1C). No other pathology of coronary arteries was present.

The patient was treated surgically by a bioprosthetic aortic valve replacement. The coronaro-pulmonary fistula was evaluated as hemodynamically insignificant and was not treated.

In the early postoperative period, a permanent complete atrioventricular block occurred, and a pacemaker had to be implanted. The patient's recovery was subsequently uneventful, and one month after the cardiac surgery the patient was asymptomatic. Nor- 

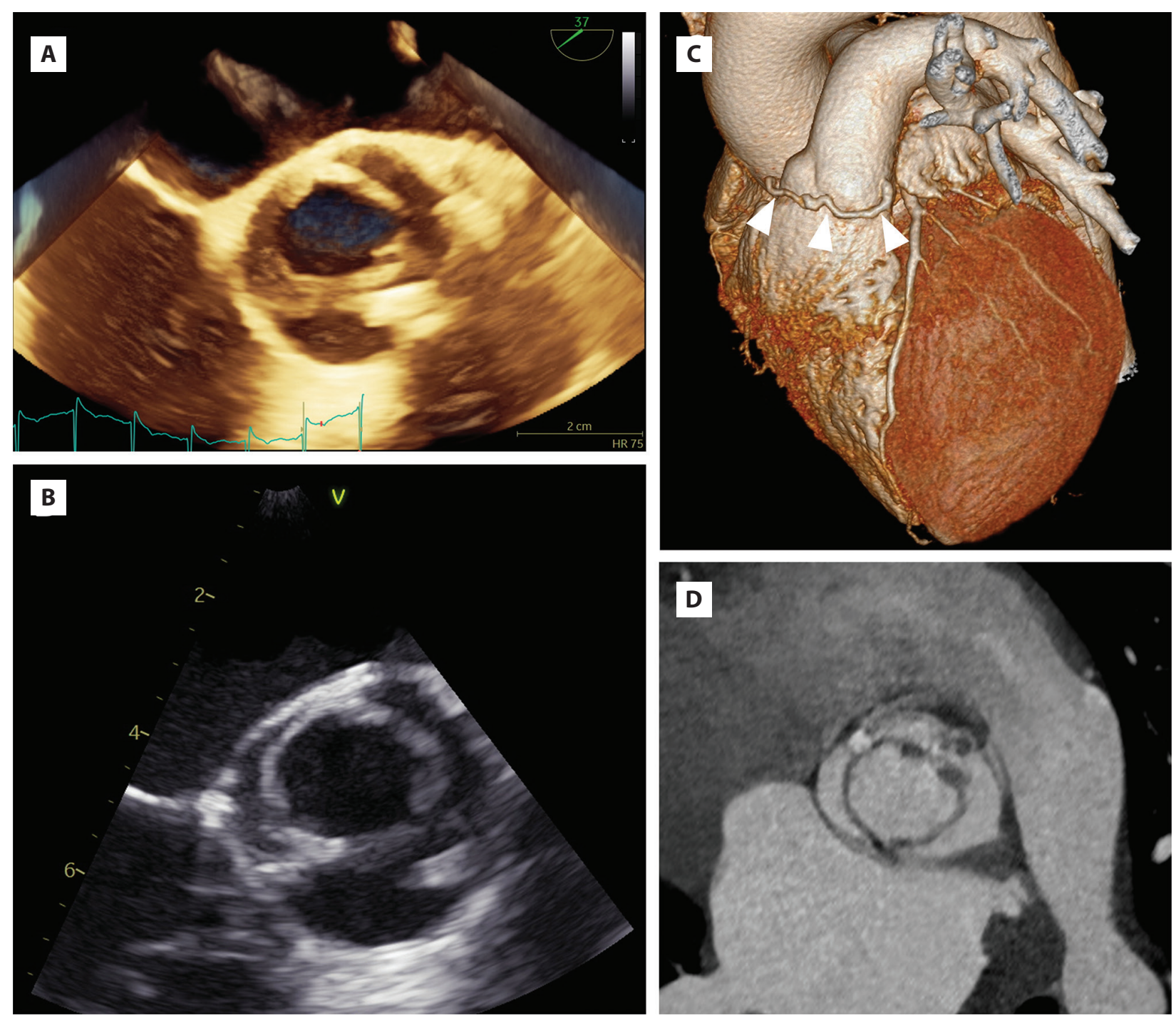

Figure 1. A. Transesophageal 3D echocardiography, aortic valve view depicting unicommissural unicuspid aortic valve. B. Transesophageal 2D echocardiography, upper esophageal aortic short-axis view showing unicuspid aortic valve. C. Cardiac computed tomography, 3D volume rendering technique showing the coronary-pulmonary fistula (arrows). D. Cardiac computed tomography, oblique axial minimum intensity projection showing unicuspid aortic valve with leaflet thickening and presence of calcification

mal functions of aortic bioprosthesis and left ventricule in systole were found by transthoracic echocardiography.

\section{Supplementary material}

Supplementary material is available at https://journals. viamedica.pl/kardiologia_polska.

\section{Article information}

Conflict of interest: None declared.

Open access: This article is available in open access under Creative Common Attribution-Non-Commercial-No Derivatives 4.0 International (CC BY-NC-ND 4.0) license, allowing to download articles and share them with others as long as they credit the authors and the publisher, but without permission to change them in any way or use them commercially. For commercial use, please contact the journal office at kardiologiapolska@ptkardio.pl.

\section{REFERENCES}

1. Golińska Grzybała K, Kabłak-Ziembicka A, Gackowski A. Unicuspid aortic valve prolapse with severe regurgitation. Kardiol Pol. 2021;79(4):465-466, doi: 10.33963/KP.15862, indexed in Pubmed: 33687871.

2. von Stumm M, Sequeira-Gross T, Petersen J, et al. Narrative review of the contemporary surgical treatment of unicuspid aortic valve disease. Cardiovasc Diagn Ther. 2021; 11(2): 503-517, doi: 10.21037/cdt-20-814, indexed in Pubmed: 33968629.

3. Zeina AR, Blinder J, Rosenschein $\mathrm{U}$, et al. Coronary-pulmonary artery fistula diagnosed by multidetector computed tomography. Postgrad Med J. 2006; 82(969): e15, doi: 10.1136/pgmj.2005.044172, indexed in Pubmed: 16822914 